\title{
EVALUASI PELAYANAN YANG DIBERIKAN OLEH PERAWAT DALAM SISTEM PEMBERIAN ASUHAN KEPERAWATAN DI RUMAH SAKIT
}

\author{
Muhaini Atmayana Purba / 181101131 \\ muhainipurba21@gmail.com
}

\begin{abstract}
ABSTRAK
Latar belakang : Layanan keperawatan adalah bagian dari layanan rumah sakit yang mendukung proses penyembuhan dan pemulihan pasien. Kualitas layanan keperawatan mencerminkan kualitas layanan kepada pasien. Model Keperawatan Profesional Praktek (MPNP) adalah metode untuk meningkatkan kualitas asuhan keperawatan. Tujuan : Tujuan penulisan ini yaitu mengidenifikasi evaluasi pelayanan yang diberikan oleh perawat dalam sistem pemberian asuhan keperawatan di rumah sakit. Metode : Metode yang digunakan merupakan literatur review atau suatu perbandingan atau analisis antara satu jurnal dengan jurnal lainnya dari berbagai sumber seperti referensi jurnal, buku teks dan e-book. Hasil : Hasil penelitian menunjukkan kepatuhan perawat dengan standar asuhan keperawatan terhadap kinerja perawat di lingkungan dengan MPNP rata-rata adalah 92,61\%, menuju MPNP rata-rata adalah 77,64\%, dan non MPNP berada di rata-rata 75,99\%. Berdasarkan persepsi perawat, kinerja di bangsal dengan MPNP rata-rata 3,35, di bangsal menuju MPNP rata-rata 2,85, dan di bangsal non MPNP rata-rata 2,81. Kesimpulan : Kinerja di bangsal dengan MPNP berada dalam kategori baik, di bangsal menuju MPNP juga berada di kategori baik, sedangkan di bangsal non MPNP berada pada kategori sedang, terdapat perbedaan signifikan pada kinerja antara bangsal dengan MPNP, menuju MPNP dan non MPNP. Manajemen Rumah Sakit Grhasia harus mengadopsi MPNP sistem perawatan keperawatan di semua bangsal.
\end{abstract}

Kata Kunci : Evaluasi pelayanan, perawat, asuhan keperawatan, rumah sakit.

\begin{abstract}
Background : Background: Nursing services are part of hospital services that support the healing and recovery process of patients. The quality of nursing services reflects the quality of service to patients. The Professional Nursing Practice Model (MPNP) is a method for improving the quality of nursing care. Purpose : The purpose of this paper is to identify the evaluation of services provided by nurses in the nursing care system at the hospital. Method : The method used is a literature review or a comparison or analysis of one journal with other journals from various sources such as journal references, textbooks and e-books. Results : The results showed that nurses' compliance with nursing care standards to the performance of nurses in an environment with an average MPNP was $92.61 \%$, towards an average MPNP was $77.64 \%$, and non MPNPs were at an average of $75.99 \%$. Based on nurses' perceptions, performance on the ward with MPNP averaged 3.35, on the ward to MPNP an average of 2.85, and on the non MPNP ward an average of 2.81. Conclusion : Performance on the ward with MPNP is in the good category, on the ward to MPNP is also in the good category, while on the non MPNP ward is in the medium category, there is a significant difference in performance between the ward with MPNP, towards MPNP and non MPNP. The management of Grhasia Hospital must adopt the MPNP nursing care system in all wards.
\end{abstract}

Keywords : Evaluation of services, nurses, nursing care, hospitals. 


\section{Latar Belakang}

Pencapaian kualitas asuhan keparawatan di rumah sakit saat ini belum ada standar yang baku. Tuntutan masyarakat dalam pelayanan kesehatan beraneka ragam, untuk menjawab hal tersebut penting adanya pelayanan keperawatan yang reintegrasi. Pelayanan keperawatan merupakan bagian dari pelayanan kesehatan rumah sakit yang akan mendukung proses penyembuhan dan pemulihan kesehatan pasien yang dirawat, serta mutu pelayanan keperawatan akan mencerminkan mutu pelayanan pada pasien.

Model Praktik Keperawatan Profesional (MPKP) merupakan cara untuk meningkatkan mutu pelayanan asuhan keperawatan. Model Praktik Keperawatan Profesional (MPKP) adalah suatu sistem (struktur, proses dan nilai-nilai profesional) yang memungkinkan perawat profesional mengatur pemberian asuhan keperawatan, termasuk lingkungan untuk menopang pemberian asuhan tersebut. Pada tahun 1997, di RSUPN Dr. Ciptomangunkusumo telah dikembangkan MPKP dengan sistem pemberian asuhan keperawatan menggunakan model tim-primer.
Kemudian pada bulan Juli 1999, model ini juga dikembangkan di RSUP Dr. Sardjito, Yogyakarta pada beberapa ruang rawat inap sebagai percontohan.

Menurut penelitian, kinerja keperawatan pada umumnya belum memenuhi standar asuhan keperawatan, terutama dalam hal pengkajian keperawatan, perumusan diagnosis, perencanaan, pelaksanaan, dan evaluasi yang semuanya masih dalam rata-rata cukup. Hasil penelitian lainnya menyoroti bahwa asuhan keperawatan pada pasien rata-rata kategori cukup $(42,464)$, sehingga belum memenuhi standar pelayanan perawatan terkait dengan kinerja perawat sebagai pelaksananya yang dimanifestasikan dalam bentuk penampilan kerja. Lebih lanjut penelitian yang lain juga menjelaskan bahwa adanya korelasi positif antara pengetahuan, persepsi, dan sikap perawat terhadap MPKP dengan kinerja. Rumah Sakit Grhasia adalah rumah sakit pemerintah Provinsi Daerah Istimewa Yogyakarta (DIY) yang khusus melayani kesehatan jiwa. Saat ini ruang perawatan RS Grhasia Yogyakarta dapat dikategorikan menjadi tiga ruangan berdasarkan pelaksanaan MPKP yaitu ruang MPKP (kelas 1 putra), yang sudah 
melaksanakan MPKP selama hampir 2 tahun, ruang persiapan MPKP (L2), dan ruang non-MPKP (L2A, P2, P2A).

Adanya perbedaan pada sisi manajemen ruangan bisa berdampak pada perbedaan karakteristik ruangan itu sendiri. Secara umum perbedaan karakteristik ruangan dapat ditinjau dari metode pemberian asuhan keperawatan paling banyak yang digunakan di ruang MPKP dan persiapan MPKP adalah model tim-primer atau model tim modifikasi seperti yang dilakukan di RS Grhasia. Adapun pada ruangan nonMPKP, ruangan menggunakan model kasus.

Perubahan manajemen ruangan bisa mengakibatkan iklim atau kondisi kerja yang berbeda. Dampak dari perbedaan yang dirasakan secara personal pada perawat mungkin saja terjadi. Dari hasil observasi dan wawancara terhadap perawat di ruang MPKP didapatkan fakta kinerja asuhan keperawatan di ruangan MPKP lebih terintegrasi, ruang persiapan MPKP masih mencari model dan kesibukan mempersiapkan format-format yang akan digunakan, serta sebagian stafnya diikutkan pelatihan sehingga ruangan tersebut masih terlihat belum tertata, sedang di ruang non-MPKP sebagaian perawat merasa nyaman karena tidak dituntut apa-apa dan sebagian ingin meniru apa yang dilakukan oleh ruangan MPKP dengan alasan mencerminkan pelaksanaan pelayanan profesional, mulai dari pengkajian pasien sampai dengan catatan asuhan keperawatan.

\section{Tujuan}

Tujuan penulisan ini yaitu mengidenifikasi evaluasi pelayanan yang diberikan oleh perawat dalam sistem pemberian asuhan keperawatan di rumah sakit.

\section{Metode}

Metode yang digunakan merupakan literatur review atau suatu perbandingan atau analisis antara satu jurnal dengan jurnal lainnya dari berbagai sumber seperti referensi jurnal, buku teks dan e-book.

\section{Hasil \& Pembahasan}

Uji normalitas dengan kolmogorov-smirnov Test dilakukan sebelum menentukan uji hipotesis. Dari hasil uji normalitas didapatkan hasil data tidak terdistribusi normal dengan nilai $\mathrm{p}=0,000$ untuk data hasil studi dokumentasi dan data terdistribusi normal dengan nilai $\mathrm{p}=0,200$ untuk data hasil kuesioner perawat. Data dikatakan terdistribusi normal jika nilai 
taraf signifikansi atau nilai $\mathrm{p}>0,05$. Terdapat perbedaan pengkajian antara ruang MPKP, persiapan MPKP, dan non-MPKP yang secara statistik didapatkan nilai $\mathrm{p}=0,047 \quad(\mathrm{p}<0,05)$ berarti ada perbedaan yang bermakna. Menurut Ulaen1 dari hasil penelitiannya menyatakan adanya peningkatan yang sangat bermakna dengan adanya penerapan MPKP. Adanya pemahaman yang baik tentang SAK, maka standar pengkajian akan dilaksanakan dengan baik tanpa adanya kesulitan. Pelaksanaan standar diagnosa di ruang MPKP $(81,67) \quad$ lebih tinggi dibandingkan ruang persiapan MPKP $(48,63)$ dan non-MPKP $(46,67)$, secara statistik di peroleh nilai $\mathrm{p}=0,001$ $(\mathrm{p}<0,05)$ berarti ada perbedaan yang bermakna. Model MPKP perawat menggunakan kemampuan critical thingking dengan baik untuk dapat mengidentifikasi data-data pasien. Kinerja dalam dokumentasi perencanaan tampak bahwa ruang MPKP $\quad(90,00)$ lebih tinggi dibandingkan ruang persiapan MPKP $(74,00)$ dan non-MPKP $(65,00)$, secara statistik didapatkan nilai $\mathrm{p}=0,001$ $(\mathrm{p}<0,05)$ berarti ada perbedaan yang bermakna. Oleh karena itu, perencanaan keperawatan yang lengkap akan menentukan intervensi keperawatan yang akan dilaksanakan, model MPKP menjamin kontinuitas perawatan pasien. Pelaksanaan tindakan antara ruang MPKP, persiapan MPKP dan nonMPKP tidak terdapat perbedaan yang bermakna hal itu mungkin dikarenakan karakteristik dari pasien yang perlu ditangani hampir sama, selain itu terdapat protap untuk penanganan atau tindakan dari setiap masalah/kasus. Pelaksanaan evaluasi tidak terdapat perbedaan yang bermakna antara ruang MPKP, persiapan MPKP, dan nonMPKP. Namun ruang MPKP lebih tingggi $(100,00)$ dibandingkan dengan ruang persiapan MPKP $(90,00)$ dan non MPKP (92,50). Pelaksanaan catatan asuhan keperawatan terdapat perbedaan antara ruang MPKP, persiapan MPKP, dan non-MPKP terhadap standar catatan asuhan keperawatan, yang secara statistik didapatkan nilai $\mathrm{p}=0,001$ $(\mathrm{p}<0,05) . \quad$ Nuryandari menyatakan peningkatan catatan asuhan keperawatan di ruang MPKP karena dalam MPKP model tim-primer.

\section{Kesimpulan \& Saran}

Dari hasil penelitian ini dapat diambil kesimpulan bahwa berdasarkan kepatuhan terhadap standar asuhan keperawatan, kinerja perawat di ruang 
MPKP dan persiapan MPKP terhadap kepatuhan SAK termasuk dalam kategori baik, sedangkan kinerja perawat di ruang non-MPKP terhadap SAK termasuk dalam kategori cukup. Berdasarkan persepsi perawat kinerja di ruang MPKP dalam kategori baik, sedangkan dari ruang persiapan MPKP dan non-MPKP dalam kategori cukup. Terdapat perbedaan antara kinerja di ruang MPKP, persiapan MPKP dan non-MPKP terhadap kepatuhan standar asuhan keperawatan.

\section{Daftar Pustaka}

Achmadi, Luthfiani. Dkk. (2015).

Gambaran Tingkat Pengetahuan

Perawat Dalam Penerapan

Standart Asuhan Keperawatan DI

Ruangan Rawat Inap Interna RSUD Datoe Bhinangkara.

Asmadi. 2008. Konsep Dasar Keperawatan. EGC. Jakarta

Bidang Perawatan RS Grhasia. (2006).

Standar Asuhan Keperawatan

Kesehatan Jiwa Rumah Sakit

Grhasia. Cetakan Pertama : Yogyakarta.

Notoadmojo, S. (2003). Prinsip-prinsip

Ilmu Kesehatan Masyarakat.

Penerbit Rhineka Cipta, Jakarta.

Simamora, R. H. (2008). Peran

Manajer Perawat Dalam
Pembinaan Etika Perawat

Pelaksana Dalam Peningkatan

Kualitas Asuhan Keperawatan.

IKESMA

Nursalam. (2002). Manajemen Keperawatan Aplikasi dalam Praktik Keperawatan Profesional. Penerbit Salemba Medika. Cetakan Pertama, Jakarta.

Potter dan Perry. 2005. Fundamental Keperawatan Konsep Proses dan Praktik. Edisi 4. EGC. Jakarta.

Priharjo, Robert. 2008. Konsep \& Perspektif Praktik Keperawatan Profesional. Jakarta: EGC.

Rahmat, Ibrahim, dkk. (2012). Evaluasi Pelaksanaan Sistem Pemberian Asuhan Keperawatan di Ruang Rawat Inap Terhadap Kinerja Perawat. Berita Kedokteran Masyarakat, Vol 28 No 1.

Simamora, R. H. (2008). Peran Manajer Perawat Dalam Pembinaan Etika Perawat Pelaksana Dalam Peningkatan Kualitas Asuhan Keperawatan. IKESMA

Simamora, R. H. (2009). Dokumentasi Proses Keperawatan. Jember. University Press

Simamora, R. H. (2010). Komunikasi Dalam Keperawatan. Jember: University Press 
Suarli dkk (2010) Manajemen

Keperawatan Dengan Pendekatan

Praktis.Erlangga: Jakarta.

Susanto Rachmat.2010. Penerapan

Standar Asuhan Keperawatan Di

Puskemas Rawat Inap Cilacap.

Wahid, Abdul. (2012). Dokumentasi

Proses Keperawatan. Yogyakarta

:PT. Nuha Medika 